\title{
Survival Factors of Motorcycle Ambulances Made in Bobo- Dioulasso, Burkina Faso, West Africa
}

\section{Schlumberger ${ }^{1}$, M. Kone ${ }^{2}$, E. Betsem ${ }^{3}$, A. Saignol ${ }^{4}$, I. Sombie ${ }^{5}$, J. Testa ${ }^{6}$, C. Sanou ${ }^{7}$, O. Dufriche ${ }^{8}$, B. Eichwald ${ }^{9}$, Y. Savadogo ${ }^{10}$}

${ }^{1}$ Martin Schlumberger, Agence de Médecine Préventive (AMP), Bobo-Dioulasso, Burkina Faso

${ }^{2}$ Mahomed Kone, Institut Supérieur des Sciences de la Santé (INSSA), Bobo-Dioulasso, Burkina Faso

${ }^{3}$ Edouard Betsem, AMP, Bobo-Dioulasso, Burkina Faso

${ }^{4}$ Alain Saignol, Burkina-Secours (BS), Bobo-Dioulasso, Burkina Faso,

${ }^{5}$ Issiaka Sombie, West African Health Organization (WAHO), Bobo-Dioulasso, Burkina Faso

${ }^{6}$ Jean Testa, Centre Muraz, Bobo-Dioulasso, Burkina Faso

${ }^{7}$ Christophe Sanou, AMP, Bobo-Dioulasso, Burkina Faso

${ }^{8}$ Odile Dufriche, PREvention de la mortalité Maternelle et Infantile et Soins de Santé VIH/SIDA dans les régions de Bobo et Banfora (PREMISS-BB), Direction Régionale de la Santé des Hauts-

Bassins (DRSHB), Bobo-Dioulasso, Burkina Faso

${ }^{9}$ Bernard Eichwald, 31 Bd Raimbaldi, Nice 06000, France

${ }^{10}$ Yacouba Savadogo, DRSHB, Bobo-Dioulasso, Burkina Faso

\begin{abstract}
:
Introduction: Motorcycle Ambulances (MA) have been used for rural urgencies in Burkina Faso, West-Africa, since 1976. 320 MA were built, between 1984 and 2013, in Bobo-Dioulasso, second town of the country located in its Western part. The main sponsor was a program for very indebted poor countries funded by Switzerland. This mean of transport in urgency, still in use in Burkina Faso, has since been adopted by many African countries.
\end{abstract}

Aim of the Study: Determine factors which significantly modified survival of MA.

Methods: 63 MA manufactured in Bobo-Dioulasso (1997-2012), and delivered around to 51 Health Centers (HC), have been looked after, taken in picture and a questionnaire was filled-up in 2014 after community and medical staff interview, to determine, in a retrospective cohort analysis, factors which affected MA lifespan in HC. Data were collected in Excel@ and Stata $\odot$. Kaplan-Meier survival curves were drawn, and significant factors in univariate and multivariate analysis were sorted by Cox.

Results: Seven MA have been found unused by $\mathrm{HC}$, one which was delivered unworkable, five due to refusal of the population, and one by refusal of health staff. 3021 sanitary evacuations were conducted by the remaining $56 \mathrm{MA}$ which showed a medium survival of 8 months, a mean survival of 22 months and a maximum survival of 52 months. In multivariate analysis, only one factor has significantly modified MA survival: A motorcycle brand used to elaborate MA, Jianshe $\odot$, imported from Popular China, which decreased MA lifespan $(p=0.03)$. Factors which showed, in multivariate analysis, no significant effect on MA survival were: total number of consultations done by HC $(p=0.66)$, total distance covered by MA in lifespan $(p=0.70)$, the presence of a mechanic with MA spare parts $(p=0.28)$ and presence of a complementary health insurance for the HC population ( $p=0.06)$.

Conclusion: This study underscores the Switzerland's program benefits on well-being of remote village populations, but the survival of MA was too short. We recommend organizing a better sensitization of rural communities and sponsors on maintenance before delivering MA and release left-over MA to other HC in need of a mean of evacuation. Maintenance of MA must be implemented by the MA production unit, on the mode of ambulance-cars maintenance.

Keywords: motorcycle ambulance, survival analysis, Cox, Burkina Faso, West-Africa, Switzerland. 


\section{Schlumberger et al.}

\section{INTRODUCTION}

The idea to quickly transport wounded soldiers with Motorcycle Ambulances (MA) grew during World War 1 [1]. The strategy, in 1972, to carry quickly sick patients on a stretcher, fixed on a threewheel bicycle, was developed in India during cholera epidemics [2].

In 1975, in the context of support of a Non Governmental Organization (NGO) "Brothers to All Men" to Fada N'Gourma's Medical Region (Burkina Faso, West-Africa), two volunteers (Martin Schlumberger and Bernard Eichwald) incorporated a stretcher on a Motobecane $\odot$ motorcycle. A strengthened MA, built in France (Nice), was the subject of a video documentary, diffused in Burkina Faso and over the world in 1988 [3]. MA was later produced by NGO "Burkina Secours" (BS) in Bobo-Dioulasso, a city of West Burkina Faso [4].

Following craftsmanship production, at small scale, of MA, since 1990, BS organized serial production of $160 \mathrm{MA}$ with incorporated stretcher or trailer (figure 1) on Peugeot $\odot$ and Yamaha $\odot$ motorcycles, in a local African assembly unit, run by polio handicapped volunteers, so lowering cost of MA for sponsors.

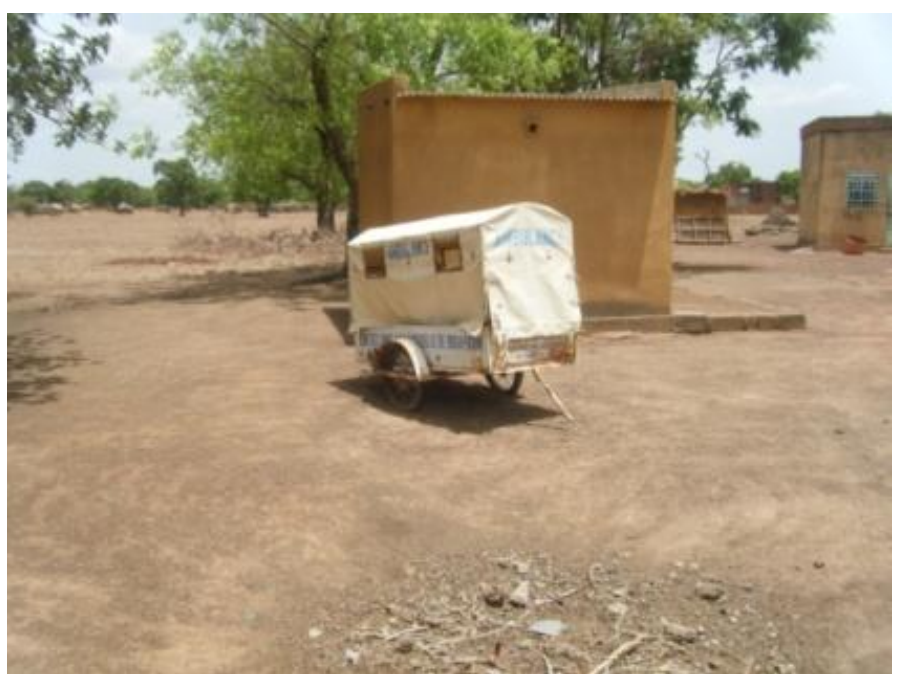

Figure1. An Out-Of-Order Ambulance Trailer Tracked by Motorcycle to Carry out Evacuees (Bouahoun HC, Hounde HD), HVR, Burkina Faso (2014)

In 1992, in the context of "Poor Countries Debt Relief Program" (PCDRP) [5], Switzerland gave BS funds to produce $250 \mathrm{MA}$, built from a motorcycle Jianshe $\odot$ from Popular China at a unitary cost of 2,500 US\$ (2004) (figure 2).

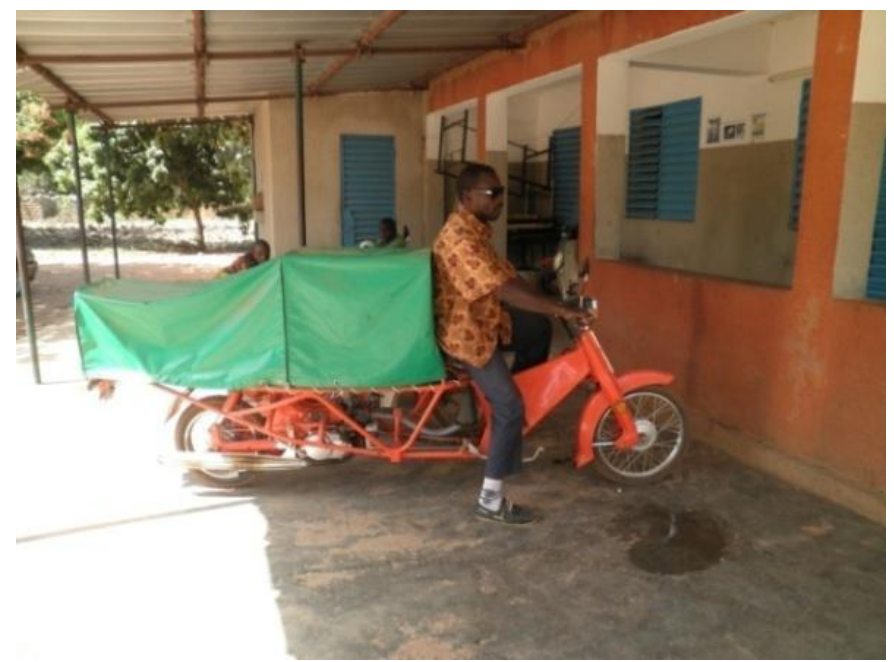

Figure2. A motorcycle ambulance (Jianshe $\odot$ bicycle model) photographed in 2013 in Bama HC, Dande HD, HVR, Burkina Faso (2014)

In 2005, Jean-François Bakyono made a survey on 45 MA of Région des Hauts-Bassins or "High Valleys Region" (HVR) around Bobo-Dioulasso [6] (table 1). Health Centers (HC) were in charge of MA, most of the time with financial control by a local "Management Committee" (MC), asking, for 
transfer of patients, a contribution, on average, of 5 US\$, against 30 US\$ with Four-Wheel Drive (FWD) ambulance-cars.

Table1. Type of urgencies made in HVR by 45 MA (2000-5) (Burkina Faso)

\begin{tabular}{|c|c|}
\hline Category & $\mathbf{N}$ \\
\hline Obstetrics & $220(40 \%)$ \\
\hline Surgery & $150(27 \%)$ \\
\hline Medicine & $120(22 \%)$ \\
\hline Others & $60(11 \%)$ \\
\hline Total & $550(100 \%)$ \\
\hline
\end{tabular}

Along Burkina Faso, many African countries, in small scale, imported or developed MA: Mali [7, 8], Sierra Leone [9], Guinea-Bissau [10], Uganda [11], South-Sudan [12], South-Africa which inspired many countries [13], Chad [14], Guinea-Conakry [15], Senegal [16], Niger [17], and Democratic Republic of Congo [18]. Hoffman in Malawi has shown also the benefits of MA in obstetrical urgencies [19]. However all those African countries have small number of MA, conducting to descriptive publications. Only Burkina Faso has produced MA at big scale and locally, giving opportunity to conduct analytical studies.

\section{AIM OF THE STUDY}

Define factors which interfere significantly with survival of MA built and used in HVR.

\subsection{Type of Study}

Retrospective Cohort

\subsection{Place of Study}

HVR, with 9.3\% of Burkina Faso surface, hold, at time of study, 1,989,361 inhabitants (10\% of country's population). Seven Medical Districts (MD) are located in HVR (Orodara, Dande, Karankasso-Viguë, Hounde, Lena, Do and Dafra), harboring 162 HC, with 51 (32\%) having received one or more MA of the study.

\section{EQUIPMENT AND METHODS}

\subsection{Equipment}

In 2014, from the 66 MA produced by BS in Bobo-Dioulasso and assigned to $\mathrm{HC}$ at random in HVR, 63 MA were investigated [20]. Three MA were not investigated for security reasons, located in HVR at the border of Mali-Burkina Faso.

\subsection{Methods}

\subsubsection{Collection of Data}

Between February and June 2014, all documents concerning MA in HVR were analyzed: HC and MD medical reports of urgency transfers, MA record books and past MA questionnaires conducted in HVR [5]. MA were examined and taken in picture. Financial data were collected from MC. A standard questionnaire collected MA data : MA sponsor, motorcycle brand, type of canvas, BS registration number (notified on a plaque fixed on MA canvas), total kilometers run, as recorded by milometer or calculated from MA record book, date of arrival of MA in HC, number of transfer of sick patients from home to $\mathrm{HC}$ or from HC to hospital, as recorded by MC or, if available, a local Complementary Health Insurance (CHI), driver's training and retribution, presence of concrete road near $\mathrm{HC}$, and maintenance by a motorcycle mechanic with available spare parts for HC's MA.

Data were collected in Excel@ tables [21] and transferred to Stata $\odot$ [22].

\subsubsection{Data Analysis}

Data on Stata were analyzed, in univariate and multivariate, by Cox method. In multivariate, only factors with a $\mathrm{p}$ at most 0.20 have been included [22]. Final results in multivariate were considered significant when $\mathrm{p}$ was under 0.05 .

No anterior censorship had to be included in the Cox analysis, because date of MA arrival in HC was precisely known by BS. No posterior censorship had to be taken in account because date of "death" was known by MC and has occurred for all active MA investigated. 


\section{RESULTS AND DISCUSSION}

\subsection{MA Population Description}

Figure 3 shows trademarks and date of transfer to $\mathrm{HC}$, by year, for the 63 MA included in study.

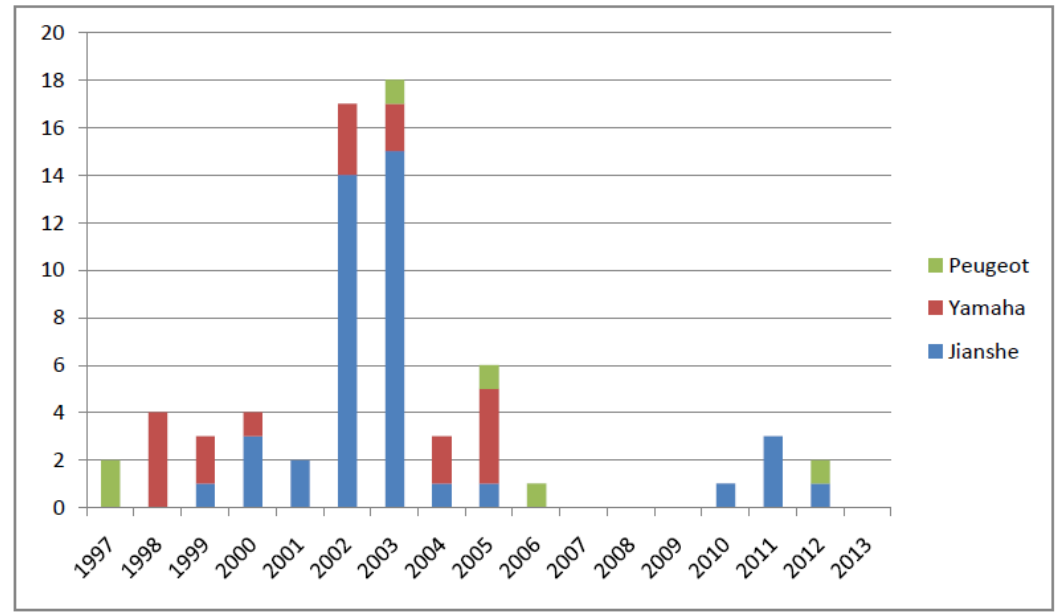

Figure3. Distribution, by motorcycle mark and by year, of attribution to health centers, for the 63 motorcycle ambulances included in the survival study, HVR, Burkina Faso (2014)

\subsection{Survival Factors Analysis}

Seven MA could not be included in the survival study because staying inactive when sent to HC. One (in HC Mahon) because the MA was delivered out-of-order, one (in HC Diama) because population refused a MA with two-wheel trailer (figure 1), three MA (one in HC Tigan, two in HC KarankassoViguë) because the population estimated that the stretcher, covered with a hood protecting the patient from rain (figure 2), gave to MA the aspect of a "hearse", one (in HC Bama) because of the donation, at the same time, of a FWD ambulance-car, and one, in HC Guema, because the medical staff refused to evacuate patients with MA. The different MA trades, with their year of HC inclusion in the study, are presented figure 3.

The benefit of covering stretcher by plastic hood, in case of rain, and which could be removed in dry season, was not openly discussed with the population, necessary to protect patients in rainy season (May-September). Many MC provided rainy coats to MA driver. Unused MA should have been forwarded to $\mathrm{HC}$ in need of a patients transfer mean, when their MA became out-of-use.

3,021 sanitary evacuations have been made by the remaining active 56 MA. The beneficial aspect of MA is evident on this number, even if a Death Averted Life Years (DALY) study was not possible with a retrospective study of this type. On survival curve (Kaplan-Meier) MA medium survival was 8 months, mean survival 22 months and maximum survival 62 months (figure 4). The Kaplan-Meier curve shows the classic picture of biologic survival curve.

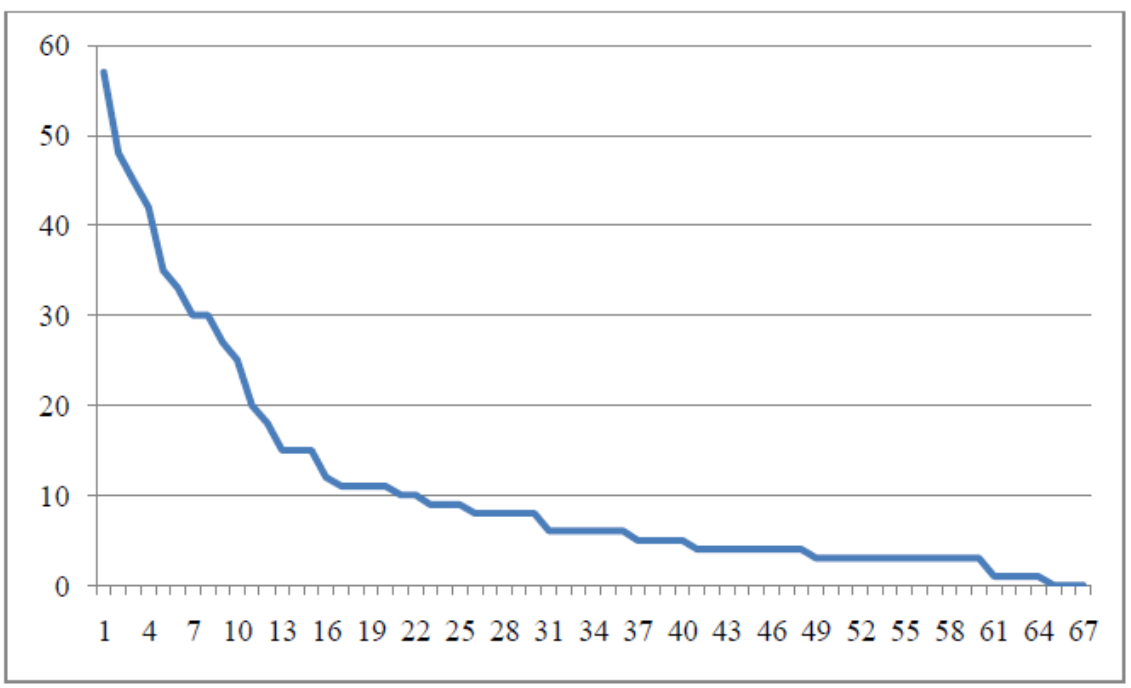

Figure4. Kaplan-Meier curve showing span of survival, in months, of the 56 MA analyzed in the lifespan study, HVR, Burkina Faso (2014) 
In univariate (table 2) and multivariate (table 3 ) are shown factors which could interfere with MA survival. In multivariate analysis, only one factor has significantly $(\mathrm{p}=0.03)$ modified (decreasing) MA survival: the use of motorcycle brand Jianshe $\odot$, from Popular China.

Table2. Analysis, by univariate Cox, of factors susceptible to interfere with MA survival (HVR, Burkina Faso, 2014)

\begin{tabular}{|c|c|c|c|}
\hline Univariate significant factors & $\mathrm{RR}$ & $95 \% \mathrm{CI}$ & $\mathrm{p}$ \\
\hline Local CHI & 0,45 & $0,39-0,85$ & 0.01 \\
\hline $\mathrm{MC}$ & 0,60 & $0,21-1,67$ & 0.33 \\
\hline Driver paid & 0,62 & $0,29-1,32$ & 0.21 \\
\hline Yamaha@MA & 0,657 & $1,12-3,48$ & 0.67 \\
\hline Peugeot@MA & 0,664 & $0,20-2,21$ & 0.50 \\
\hline Mechanic and MA spare parts & 0,67 & $0,39-1,15$ & 0.13 \\
\hline MA with trailer & 0,83 & $0,36-1,90$ & 0.66 \\
\hline HC near concrete & 0,90 & $0,52-1,55$ & 0.70 \\
\hline Number HC consultations/year & 0,995 & $0,986-1,003$ & 0.18 \\
\hline Number MA evacuations/year & 0,999 & $0,992-0,999$ & 0.22 \\
\hline Number kms performed before death of MA & 0,999 & $0,9997-0,9999$ & 0.03 \\
\hline Mean evacuation length of time & 0,999 & $0,993-1,005$ & 0.82 \\
\hline MA tricycle & 1,03 & $0,49-2,20$ & 0.92 \\
\hline MA bicycle & 1,14 & $0,63-2,05$ & 0.66 \\
\hline Driver trained & 1,19 & $0,64-2,24$ & 0.58 \\
\hline Jianshe@ MA & 1,98 & $1,25-3,48$ & 0.02 \\
\hline
\end{tabular}

Table3. Analysis, by multivariate Cox, of factors susceptible to interfere with MA survival (HVR, Burkina Faso, 2014)

\begin{tabular}{|l|c|c|c|}
\hline \multicolumn{1}{|c|}{ Multivariate significant factors } & RR & 95\% CI & p \\
\hline Local CHI & 0.50 & $0.25-1.03$ & 0.06 \\
\hline Number HC consultations/year & 0.998 & $0.994-1.002$ & 0.66 \\
\hline Number of kms performed before death of MA & 0.999 & $0.999-1.000$ & 0.70 \\
\hline Mechanic and MA spare parts & 1.27 & $0.68-2.36$ & 0.28 \\
\hline Jianshe@ MA & $\mathbf{1 . 9 3}$ & $\mathbf{1 . 0 5 - 3 . 5 8}$ & $\mathbf{0 . 0 3}$ \\
\hline
\end{tabular}

Validity and reliability of the data collected: With an administrative location of MA, we can consider that different types of MA were distributed at random. With the big number of factors which were considered as possibly modifying MA lifespan, true data quantification is difficult to ascertain. For such a retrospective study, it took a long time to consult all the documentation about MA, and discuss with MC members, mechanics and drivers, which were often illiterate. The medical student, fluent in local languages used in this part of the country, could accurately collect data and cross-compare them from different sources [20]. The composition of the team: one junior and one senior epidemiologist, diminished biases of analysis. Of course the data are limited to the African context.

If a local CHI, the presence of a mechanic with spare parts, the number of HC consultations per year and the number of kms performed before death of MA were found to be significantly beneficial to MA survival in univariate analysis, they were not significant in multivariate analysis. Multivariate analysis, taking in analysis all parameters susceptible to interfere with MA survival, was eased by the big number of MA analyzed. Burkina Faso is the only country in Africa with such a big local production and use of MA. A prospective cohort analysis would have been however more suitable for estimating MA impact on QALY. Wilson's study recommended also MA for obstetric urgencies [24].

Driver training and retribution had no significant impact on MA survival in this study but this retribution was low and the driver, which often was a $\mathrm{HC}$ caretaker or a MC volunteer, was often illiterate, without formal education, but able however to do basic MA maintenance [3].

There was also no correlation between MA survival and price charged (by km traveled) for patient's transfer, even if more money brought by MA to MC was expected to bring more funds for maintenance, and there was also no evident impact of concrete road near HC on MA survival.

The decreased survival with Jianshe $\odot$ brand was confirmed by less strength of Jianshe spare parts (engine's piston, motorcycle frame, even tubes and tires), and the difficulty to find those spare parts in rural Burkina Faso, as reported by MC. This brand was chosen by Switzerland for economic reasons, Jianshe $\odot$ being less expensive than Peugeot $\odot$ and Yamaha $\odot$ motorcycles. The presence of a local 
CHI had a significant impact on survival only in univariate, but not in multivariate analysis. Following discussion with $\mathrm{MC}$, the creation of local CHI was often the consequence of the heavy maintenance costs of Jianshe(C) MA. Difference of motorcycle brand survival should have been studied by sponsors before a large scale production by BS. Even if MA built by BS are now out-ofaction, new tricycle MA, more comfortable for patients, driver, and family assisting evacuee, but more expensive, have now the favor of sponsors and rural population (figure 5).

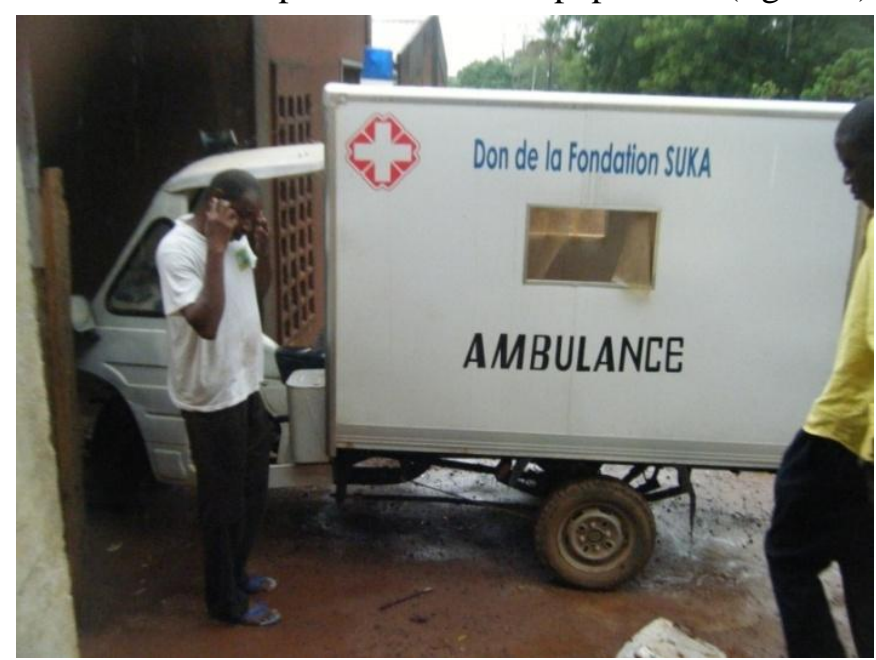

Figure5. Tricycle motor ambulance allowing to carry also family members (Dieri HC, Orodara HD), HVR, Burkina Faso (2014)

The low MA lifespan could have been increased by BS proposal of MA periodic maintenance on PCDRP budget, conducted locally by a Swiss mechanic volunteer, travelling by motorcycle, with MA spare parts at hand. He could have also increased level of competence of MA mechanics around HC. This option, proposed by BS, was not followed by a Swiss action. This type of MA maintenance follow-up has been also suggested in South-Africa [25].

\section{CONCLUSION}

MA of Jianshe $\odot$ type had a significant shorter survival. This study shows the clear benefit of MA of good quality and well maintained, when establishing a large MA network, to transfer underprivileged rural populations amid bad roads. Population sensitization and test periods must be organized by sponsors, with different MA types, brands, and mechanical follow-up, before generalization.

Burkina Faso had a long and wide experience with MA, and this study brings an invaluable witness to all African countries showing interest in this strategy of transfer of patients in difficult regions.

\section{DISCLOSURE OF INTEREST}

The authors declare that they have no conflict of interest concerning this article.

\section{REFERENCES}

[1] Röhlich P. Military motorcycles encyclopedia, 1st edition, Terres Editions (ISBN: 978-2-35530185-8), pp 30-31 (1973).

[2] Chaudhuri R.N. Management of cholera cases in rural areas, pp 263-271. In Barua D. and Burrows W. Cholera, 1st edition, WB Saunders, pp 455, (1974).

[3] Babeanu I. The Moped_Ambulance, Video production (1988). (https://vimeo.com /185226818).

[4] Saignol A., Schlumberger M., Eichwald B. and Hutin Y. Mobylettes-ambulances et évacuations sanitaires: l'expérience de « Burkina Secours » au Burkina Faso. Développement et Santé, 118, pp. 29-30 (1995).

[5] www.cepal.org/publicaciones/xml/6/4306/lc/1230i.pdf (2010)

[6] Bakyono J.F. Rapport sur l'enquête d'évaluation des motos-ambulances dans la région sanitaire des Hauts-Bassins. MPH Thesis, Ouagadougou University, Pp: 32 (2006).

[7] www.panapress.com/la-moto-ambulance-une-alternative-sure-en-milieu-rural-au-Mali--13721627-17-lang2-index.html (2012)

[8] https://www.youtube-com/watch?v=zbBfruYCOuY (2012) 
[9] https://www.unicef-org/french/infobycountry/sierraleone_53435 (2010)

[10] www.unicef.org/news/unfpa-donates-motorcycles-ambulances-save-lives-women-and-childrenrural-guinea-bissau (2013)

[11] www.dailymotion.com/videoxz3qbf_motorcycle-ambulances-save-life-in-uganda_news (2016)

[12] https://www.unicef.org/mdg/sudan_57194.html (2010)

[13] https://en.wikipedia.org/wiki/Motorcycle_ambulances\#South-Africa (2016)

[14] Presidencetchad.org/affichage_news_prd.php?id=163\&titre=\%20DES\%20MOTOS\%20AMBUL ANCES\%20POUR\%20ALLEGER\%20LES\%20FEMMES\%RURALES (2010)

[15] https://www.unicef.org/french/infobycountry/guinea_50063 (2009)

[16] htpps://www.youtube.com/watch ?v=0pwKHY5NWci (2015)

[17] www.msp.ne/index.php/les-activites-/387-10-motos-ambulances-pour-le-renforcement-de-1offre-et-de-l-acces-aux-services-de-la-sante-de-reproduction (2010)

[18] www.africatopsucces.com/2014/12/18/rdcongo-la-moto-ambulance-qui-sauve-des-vies-amousango (2014)

[19] Hoffman JJ, Dzimadzi C, Lungu K, Ratsma EY, Hussein J. Motorcycle ambulances for referral of obstetric emergencies in rural Malawi: do they reduce delay and what do they cost? Int $\mathrm{J}$ Gynaecol Obstet 2008; 2:191-7. Doi: 10.1016/j.ijgo.2008.04.001.Epub 2008 Jun 16.

[20] Kone M. Etude des facteurs d'utilisation et de survie des moto-ambulances dans la région sanitaire des Hauts-Bassins. MD thesis, INSSA (2014).

[21] MS-Excel@, www.microsoft.com (2008).

[22] Stata $\odot$, version 12. Data analysis and statistical software, www.stata.com (2012)

[23] Cox D.R. Regression models and life-tables. J R Statist Soc B, 34(2), pp 187-220. (1972)

[24] Wilson A, Hillman S, Rosato M et al. A systematic review and thematic synthesis of qualitative studies on maternal emergency transport in low and middle-income countries. Int J Gynecol Obstet, 122 (3), pp 192-201. Doi:10.1016/j.ijgo2013.03.030Epub2013Jun24 (2013)

[25] M.J. Norman, M.M. Norman. Motorcycle ambulances, an appropriate healthcare technology for developing countries. A narrative on the design of the eRanger ambulance. File://C:/Users/hp/ Downloads/ motorcycle-ambulance.pdf 